\title{
APONTAMENTOS SOBRE O SISTEMA PENITENCIÁRIO FEDERAL E O EQUILÍBRIO ENTRE SEGURANÇA PÚBLICA E AS GARANTIAS INDIVIDUAIS
}

\author{
NOTAS SOBRE EL SISTEMA PENITENCIARIO FEDERAL Y EL EQUILIBRIO ENTRE \\ SEGURIDAD PÚBLICA Y GARANTÍAS INDIVIDUALES
}

Heber Carvalho Pressuto ${ }^{1}$

\begin{abstract}
Resumo: O Sistema Penitenciário Federal é um sistema carcerário ainda novo, tendo sua existência e destinação pouco conhecidas pela população. O número relativamente baixo de cidadãos cumprindo pena em suas dependências, nas quais é vedado por lei ultrapassar a capacidade máxima, a baixa divulgação das rotinas dessas penitenciárias e a ausência de publicações acerca do tema ressaltam o distanciamento entre a população e o referido sistema. Assim, o presente artigo busca reunir as informações oficiais atualmente disponíveis, de forma a permitir um certo grau de conhecimento sobre esse tema, até então pouco lembrado pelos juristas. Na sequência, é realizada a observação e análise de algumas decisões judiciais que versam sobre os direitos dos internos destes estabelecimentos, bem como sobre os direitos de seus familiares, objetivando tecer comparações entre o Sistema idealizado e a realidade dos que estão nele insertos. Como resultado, percebe-se que a ausência de alguns problemas recorrentes nos sistemas penitenciários estaduais não permite concluir pela inexistência de pontos críticos, se revelando necessária e urgente um voltar de olhos da população e da doutrina, para uma observação constante e aprofundada do Sistema Penitenciário Federal.
\end{abstract}

Palavras-chave: Penitenciárias; Pena; Prisão; Execução Penal; Sistema Penitenciário Federal.

Resumen: El Sistema Penitenciario Federal es un sistema penitenciario aún nuevo, cuya existencia y destino son poco conocidos por la población. El relativamente bajo número de ciudadanos cumpliendo condena en sus instalaciones, en el que está prohibido por la ley exceder la capacidad máxima, la escasa difusión de las rutinas de estos centros penitenciarios y la ausencia de publicaciones sobre el tema ponen de manifiesto la distancia entre la población y el citado sistema. Así, este artículo busca recabar la información oficial actualmente disponible, con el fin de permitir cierto grado de conocimiento sobre este tema, que hasta entonces era poco recordado por los juristas. A continuación, se lleva a cabo la observación y análisis de algunas decisiones judiciales que versan sobre los derechos de los internos de estos establecimientos, así como los derechos de sus familiares, con el objetivo de realizar comparaciones entre el Sistema idealizado y la realidad de quienes están incluidos en él. Como resultado, es claro que la ausencia de algunos problemas recurrentes en los sistemas penitenciarios estatales no permite concluir que no existen puntos críticos, revelando que es necesario y urgente volver la mirada de la población y la doctrina a un observación constante y profunda del Sistema Penitenciario Federal.

Palabras llave: Penitenciarías; Pena; Prisión; Ejecución penal; Sistema Penitenciario Federal.

\footnotetext{
1 Advogado, formado em Direito pela Pontifícia Universidade Católica do Paraná em 2015, especialista em Ciências Criminais pela mesma instituição, e em Direito Médico pela Faculdade Verbo Educacional. Atuante em Cascavel, Paraná, Brasil. Endereço eletrônico: pressuto.adv@ outlook.com.
} 


\section{Introdução}

As primeiras penitenciárias federais foram inauguradas no ano de 2006, o que faz do Sistema Penitenciário Federal relativamente novo, se comparado aos sistemas estaduais. A especificidade de sua destinação, a vedação legal à superlotação e a pouca divulgação das rotinas dessas penitenciárias, somados à escassez de publicações acadêmicas acerca do tema parecem demonstrar que sua existência e destinação são pouco conhecidas pela população.

Não obstante, o SPF tem adquirido cada vez mais visibilidade, em grande parte pelo trabalho dos meios de edição e publicação de notícias, que eventualmente cobrem alguma matéria sobre fatos relacionados às pessoas privadas de liberdade submetidas ao Sistema. Estes fatos ocorrem, especialmente, nos casos de transferência de presos afamados, como “Fernandinho Beira-Mar", entre Penitenciárias Federais.

Contudo, mesmo que o conhecimento de sua existência vá sendo pouco a pouco introduzido no conhecimento da população, percebe-se que o seu funcionamento interno, sua função e seus objetivos são quase que completamente ignorados. Mais longe do conhecimento popular estão os internos do Sistema, centenas de presos que, por uma razão ou outra, estão nas prisões de maior nível de segurança e isolamento do Brasil.

Não se constata no cidadão médio um regular interesse em conhecer os sistemas penitenciários, ou a vida daqueles que lotam as celas das prisões, sendo comum que seja visto com descrédito, e interpretado como condescendência com o crime, eventuais questionamentos sobre questões estruturais das prisões, descumprimento da legislação pela administração pública e sobre outros aspectos da vida do preso, afora o fato criminoso em si.

Em relação ao Sistema Penitenciário Federal, esse tipo de distanciamento encontra maior força. Afinal, são penitenciárias que nunca estão superlotadas, sequer atingem o limite de sua capacidade, o que derruba uma das mais frequentes críticas aos sistemas penitenciários estaduais. Ademais, são destinados a presos específicos, em situações específicas, o que pode fazer deles, no imaginário popular, os piores dos piores.

A falta de divulgação de informações oficiais e publicidade sobre o Sistema, suas penitenciárias e seus internos torna difícil a superação do desconhecimento sobre o tema, mesmo entre profissionais que atuam nas ciências criminais, já bem sabedores das rotinas e agruras encontradas nas penitenciárias estaduais. 
Diante desse cenário, onde a ignorância e o desinteresse se retroalimentam, nasceu o intento em desenvolver algum trabalho que permitisse aproximar de qualquer pessoa interessada o conhecimento acerca do Sistema Penitenciário Federal e de seus internos.

Sendo poucas e raras informações oficiais, havendo impossibilidade de acesso a muitos dos documentos sobre as prisões do Sistema, ante a aura de segredo e sigilo que permeia os acontecimentos internos, pretende-se extrair e construir a sua história pelas seguintes modalidades de fontes: matérias de jornais, publicações oficiais, legislações, livros publicados sobre a criminalidade brasileira, os documentos e informações publicados por órgãos do Estado, bem como os processos judiciais propostos contra as penitenciárias.

Os processos judiciais nos quais o preso ou seus familiares demandam contra a penitenciária é interpretado como importante fonte, posto que viabiliza conhecer quais as discordâncias, quais elementos dessas penitenciárias e da sua forma de gestão são incômodos o bastante para motivar um processo judicial.

\section{Informações elementares do Sistema Penitenciário Federal}

Considerando que para muitos pode ser ignorado o processo de idealização e estruturação do Sistema Penitenciário Federal (SPF), presume-se mais proveitoso adentrar no tema exatamente pela gênese do Sistema e a evolução das normas jurídicas relacionadas, para apenas depois abordar maiores detalhes de seu funcionamento e das lides dele decorrentes.

Idealização e desenvolvimento do Sistema Penitenciário Federal e das normas a ele pertinentes

O Sistema Penitenciário Federal, gerido pelo Departamento Penitenciário Nacional (DEPEN), teve suas unidades referenciadas já no antigo parágrafo único do artigo 72 da Lei 7.210 de 1984 (Lei de Execução Penal) - a Lei 13.769 de 2018 o alterou para $§ 1^{\circ}$, mantida a mesma redação -, que versa sobre estabelecimentos penais e de internamento federais: “Incumbem também ao Departamento [Penitenciário Nacional] a coordenação e supervisão dos estabelecimentos penais e de internamento federais".

Posteriormente, tem-se ainda nova menção aos estabelecimentos penais geridos pela União, desta vez com o advento da Lei 8.072 de 1990 (Lei dos Crimes Hediondos), cujo art. $3^{\circ}$ não só menciona tais estabelecimentos como lhes aponta o objetivo, ao afirmar que os 
estabelecimentos penais da União serão de segurança máxima, “destinados ao cumprimento de penas impostas a condenados de alta periculosidade, cuja permanência em presídios estaduais ponha em risco a ordem ou incolumidade pública".

Não obstante esta função atribuída ao DEPEN, e a previsão legal de estabelecimentos penais de segurança máxima mantidos pela União, até o início do presente século o Governo Federal não inaugurara nenhum estabelecimento penal ou de internamento federal.

No ano de 2003, após uma onda de ataques ocorrida em fevereiro daquele ano, no Rio de Janeiro-RJ, supostamente organizada por Luiz Fernando da Costa, conhecido como Fernandinho Beira-Mar (BRITO, 2005), o então presidente Luiz Inácio Lula da Silva chegou a anunciar que até o final daquele mês de abril o primeiro presídio federal do país estaria pronto.

Porém, apenas alguns anos depois é que houve mudança no cenário, com a inauguração da primeira penitenciária federal na cidade de Catanduvas-PR, em 23 de junho de 2006, e a abertura da penitenciária federal em Campo Grande - MS, em 21 de dezembro daquele mesmo ano (PAIXÃO; SILVA JÚNIOR, 2013).

Gabriel Cesar dos Santos (2016) sintetiza muito bem os fatores que compuseram a fórmula que culminou nos presídios federais:

Some-se ao surgimento das organizações criminosas uma grave crise na administração do sistema penitenciário estadual, a pressão da mídia e sociedade por uma resposta urgente ao problema, e têm-se o contexto em que foram criadas as penitenciárias federais brasileiras.

Com a emergência do Sistema, percebeu-se a urgente necessidade de sua regulamentação, de forma que em fevereiro de 2007 foi aprovado, através do Decreto n ${ }^{\circ} 6.049$, o Regulamento Penitenciário Nacional, que trouxe, dentre outras coisas, uma diversidade de determinações sobre o Sistema e suas unidades penitenciárias, e fixou a capacidade máxima de 208 presos em cada penitenciária federal (art. $6^{\circ}$, inc. II).

Em 2008 foi sancionada a Lei 11.671, que “dispõe sobre a transferência e inclusão de presos em estabelecimentos penais federais de segurança máxima", a qual evidenciou serem as penitenciárias federais uma alternativa ao "sistema prisional ordinário", ou seja, os sistemas penitenciários de cada Unidade Federativa, e vedou que fosse ultrapassada a lotação máxima das penitenciárias federais (art. 11).

Diferente do que se poderia supor, o SPF não tem nenhuma relação direta com os acusados ou condenados na competência da Justiça Federal, sendo que a inclusão dos presos nesse Sistema deve ser restrito a "situações específicas de risco à ordem pública ou ao ambiente 
carcerário, bem como quando fosse necessário garantir a segurança do próprio preso" (PAIXÃO; SILVA JÚNIOR, 2013).

Para regulamentar a lei que trata da transferência e inclusão de presos no SPF foi assinado o Decreto 6.877 de 18 de junho de 2009, que apresenta as características dos presos que podem ser inclusos no SPF e das diligências necessárias quanto à documentação nos processos e na efetivação da inclusão e transferência. No mesmo período do ano houve a inauguração de mais duas penitenciárias federais: uma em Porto Velho - RO e outra em Mossoró - RN, em 16 de junho e 03 de julho, respectivamente (PAIXÃO; SILVA JÚNIOR, 2013).

A Corregedoria-Geral da Justiça Federal, do Conselho da Justiça Federal (CJF), promoveu em 2010 o "I Workshop sobre o Sistema Penitenciário Federal", visando “aproximação maior entre todos os profissionais do sistema". Para o evento foi idealizada uma "reunião de trabalho, restrita a juízes e técnicos da área" na qual deveriam ser apresentadas "propostas para aperfeiçoamento do Sistema". Foram frutos do evento 15 (quinze) "Enunciados firmados por consenso" e 10 (dez) "Entendimentos", disponíveis no livreto publicado pelo Centro de Estudos Judiciários do Conselho da Justiça Federal (2010).

Com a continuidade dos encontros, o CJF aprovou a criação do Fórum Permanente do Sistema Penitenciário Federal (2013), sendo que até os dias atuais já foram publicados livretos de 7 (sete) destes denominados workshops, todos disponíveis no sítio eletrônico do CJF.

No ano de 2018, após pelo menos três adiamentos, foi inaugurada pelo DEPEN a Penitenciária Federal em Brasília - DF, a quinta unidade penitenciária do SPF. Contudo, com apenas uma das suas quatro vivências ativa. Segundo o agente que ocupava o cargo de presidente do Sindicato dos Agentes Federais de Execução Penal em Brasília (Sindapef - DF) naquele mês de outubro, "na época em que ela seria inaugurada, em março, um dos motivos para adiamento foi a questão do efetivo [...] um dos problemas é a falta de servidores, que não foi solucionado" (STACCIARINI, 2018).

Em verdade, o processo de inauguração prematura - termo que aqui se refere ao preparo do local e do efetivo, e não quanto ao tempo levado para a inauguração - teria sido forçado, para desestruturar um suposto plano criminoso que estaria sendo elaborado por três internos da Penitenciária Federal em Porto Velho - RO. Segundo a Justiça Federal “ a transferência para a penitenciária é uma forma de isolar líderes de facções" (LIMA, 2018). Cabe uma observação, neste ponto: os três internos que foram transferidos para a Penitenciária Federal em Brasília DF já se encontravam em uma penitenciária federal, a de Porto Velho - RO, que dispõe de estrutura e sistema de segurança semelhantes. 
Em 2017 o então Ministro da Justiça e Segurança Pública, Osmar Serraglio, afirmou em um evento no Rio Grande do Sul a construção de mais cinco penitenciárias federais, sendo que uma delas seria naquele Estado e as outras em locais não informados (Ministério da Justiça, 2017). Entretanto, até o segundo semestre de 2021 não se tem notícia de nenhuma nova unidade em construção ou planejamento, de forma que, no cenário atual, o SPF abarca cinco penitenciárias federais em funcionamento, sendo que em uma delas, a de Brasília-DF, apenas parte da estrutura está ativa.

A última mudança significativa na legislação pertinente ao tema foi decorrente da denominada "Lei Anticrime", que aumentou o período máximo da permanência no Sistema Penitenciário Federal, que era de 360 dias (renováveis por igual período), para 3 (três) anos (igualmente renováveis), e fez outras diversas alterações na Lei $\mathrm{n}^{\circ} 11.671 / 2008$, que trata da transferência e inclusão de presos em estabelecimentos penais federais de segurança máxima.

\section{Aspectos processuais da inclusão e permanência nas penitenciárias federais}

A inclusão de pessoa privada da liberdade em uma Penitenciária Federal depende da observação de alguns requisitos legais em decisão judicial, não ocorrendo em razão da natureza dos crimes, ou da Justiça - Federal, Militar ou outra -, competente para o julgamento do delito pelo qual o preso é ou foi acusado.

De acordo com o art. $3^{\circ}$ da Lei $n^{\circ} 11.671 / 2008$, "serão incluídos em estabelecimentos penais federais de segurança máxima aqueles para quem a medida se justifique no interesse da segurança pública ou do próprio preso, condenado ou provisório”. Maiores detalhes ficaram a cargo do Decreto $n^{\circ} 6.877 / 2009$, que regulamenta a lei citada, e define as características do preso que poderá ser incluído em uma penitenciária federal:

Art. 3o Para a inclusão ou transferência, o preso deverá possuir, ao menos, uma das seguintes características:

I - ter desempenhado função de liderança ou participado de forma relevante em organização criminosa;

II - ter praticado crime que coloque em risco a sua integridade física no ambiente prisional de origem;

III - estar submetido ao Regime Disciplinar Diferenciado - RDD;

IV - ser membro de quadrilha ou bando, envolvido na prática reiterada de crimes com violência ou grave ameaça;

V - ser réu colaborador ou delator premiado, desde que essa condição represente risco à sua integridade física no ambiente prisional de origem; ou VI - estar envolvido em incidentes de fuga, de violência ou de grave indisciplina no sistema prisional de origem. 
Além dos requisitos listados, o artigo 11 da Lei $n^{\circ}$ 11.671/2008 determina que seja observado o limite de lotação máxima do estabelecimento, que não pode ser ultrapassada, e o $\S 1^{\circ}$ do mesmo artigo ressalta que o "número de presos, sempre que possível, será mantido aquém do limite de vagas, para que delas o juízo federal competente possa dispor em casos emergenciais".

Assim, inexistem registros de superlotação no sistema, sendo que de acordo com Conselho Nacional de Justiça (2021, p.29), o "número de presos no Sistema Penitenciário Federal representa hoje menos de 0,1\% da população prisional do país".

O processo de inclusão e transferência para o Sistema Penitenciário Federal reserva certa complexidade, envolvendo autoridades administrativas estaduais e da União, bem como dois diferentes juízos.

Segundo consta no art. $4^{\mathrm{o}}$ da Lei 11.671/2008, a admissão do preso, condenado ou provisório, no Sistema Penitenciário Federal dependerá de “decisão prévia e fundamentada do juízo federal competente, após receber os autos de transferência enviados pelo juízo responsável pela execução penal ou pela prisão provisória”.

Ou seja: para que o juízo corregedor de uma penitenciária federal possa admitir um preso em suas dependências, imprescindível que a pretensão da transferência tenha sido autuada e julgada pelo juízo responsável pela execução penal ou pela prisão provisória, geralmente denominado juízo de origem.

A análise, pelo juízo de origem, pode ter início por provocação da Autoridade Administrativa, do Ministério Público ou do próprio preso (art. $5^{\circ}$ ). No processo de transferência devem ser ouvidos, ainda, quando não requerentes, a autoridade administrativa, o Ministério Público e a defesa, bem como o Departamento Penitenciário Nacional - DEPEN, a quem é facultado indicar o estabelecimento penal federal que entender mais adequado para a inclusão daquele preso (art. $5, \S 2^{\circ}$ ).

Ao proferir sua decisão, o juízo de origem deverá fixar o prazo de permanência do preso no Sistema Penitenciário Federal, sendo que tal prazo deverá respeitar o limite de 3 (três) anos, que, contudo, é renovável (art. $5^{\circ}, \S 5^{\circ}$, e art. $10, \S 1^{\circ}$ ).

Findo o processo perante o juízo de origem, este encaminhará os autos para o juízo federal competente pela corregedoria da penitenciária federal onde se pretende a transferência do preso, onde o pedido será analisado (art. $4^{\circ}$ ). 
A inclusão poderá ser efetivada, ainda, mediante decisão precária, proferida sumariamente, nos casos em que o juízo federal competente reconheça "extrema necessidade", sendo que tal decisão poderá ser mantida ou revogada após a instrução dos autos (art. $5^{\circ}, \S 6^{\circ}$ ).

A complexidade dos procedimentos necessários pode ser melhor compreendida observando-se a Figura 1, um organograma desenvolvido pelo Departamento Penitenciário Nacional, que ilustra a publicação "Coordenação Geral de Classificação, Movimentação e Segurança Penitenciária":

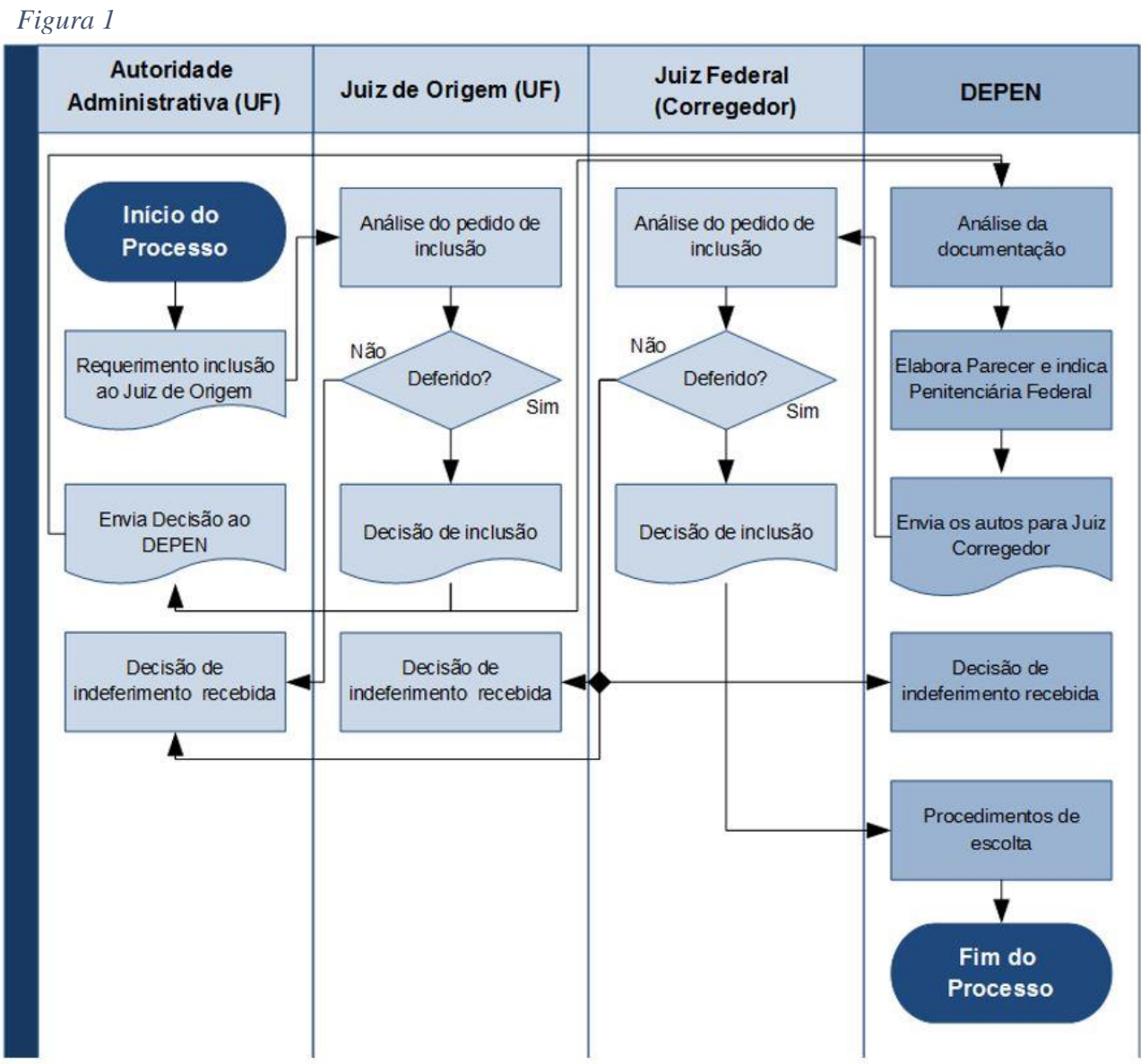

Fonte: BRASIL. Departamento Penitenciário Nacional. Coordenação Geral de Classificação, Movimentação e Segurança Penitenciária. Disponível em: 〈http://antigo.depen.gov.br/DEPEN/dispf/cgcmsp〉. Acesso em: 29 de novembro de 2021.

Havendo discordância entre o juízo de origem e o juízo federal competente, quanto à admissibilidade de um preso no Sistema Penitenciário Federal, aquele poderá "suscitar conflito de competência perante o tribunal competente, que o apreciará em caráter prioritário" (art. $\left.9^{\circ}\right)$

Uma vez incluso na penitenciária federal, o preso estará sujeito ao sistema de rodízios entre penitenciárias, prática considerada "recomendável, como boa prática penitenciária", pelo 
Enunciado $\mathrm{n}^{\mathrm{o}}$ 5, do I Workshop sobre o Sistema Penitenciário Federal, assunto que será novamente abordado mais adiante.

\section{Conhecendo as penitenciárias federais}

Estruturalmente, as Penitenciárias Federais seguem um padrão, sendo compostas por quatro blocos, denominados "vivências", e cada vivência possui quatro alas - direita e esquerda inferiores e direita e esquerda superiores. Cada ala possui diversas celas individuais, de sete metros quadrados, com dormitório, sanitário, pia, chuveiro, mesa e assento (Ministério da Justiça, 2018).

As portas das celas possuem uma chapa metálica, de forma que o preso não consegue ver o que ocorre do lado de fora. Na Figura 2, uma das poucas imagens oficiais disponíveis, que ilustra a matéria "Construtora faz entrega provisória da Penitenciária Federal de Brasília ao Depen”, publicada em 31 de outubro de 2017 no site do Ministério da Justiça e Segurança Pública, fica bem evidente esta condição:

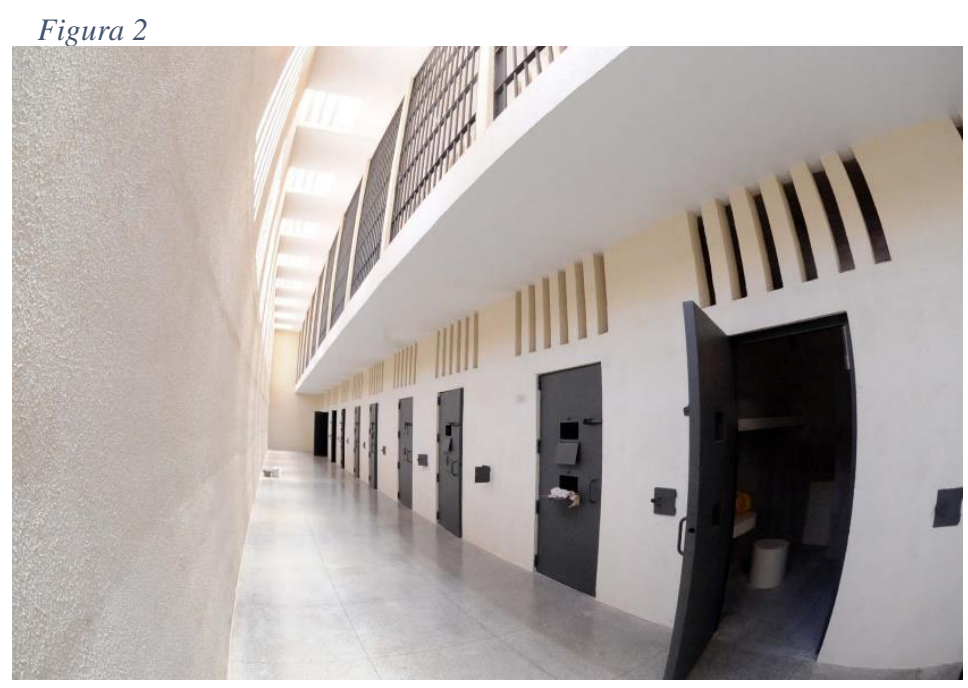

Fonte: BRASIL. Ministério da Justiça e Segurança Pública. Construtora faz entrega provisória da Penitenciária Federal de Brasília ao Depen. Brasília, 2017. Disponível em: < https://www.justica.gov.br/news/construtora-fazentrega-provisoria-da-penitenciaria-federal-de-brasilia-ao-depen>. Acesso em: 29 de novembro de 2021.

A comida e demais itens são entregues através de uma portinhola, que, afora estes momentos, permanece fechada. Os internos permanecem nestas celas a maior parte do tempo, sendo parte de sua rotina a saída, por no máximo 2 (duas) horas diárias, para o banho de sol coletivo em pátio destinado a este fim. 
No ano de 2020, em decorrência da pandemia de COVID-19, excepcionalmente as visitas foram totalmente suspensas. Porém, a análise neste artigo se voltará para a realidade anterior à pandemia, a fim de verificar como se dava o contato dos presos com o mundo exterior em períodos de normalidade.

O Regulamento Penitenciário Federal, aprovado pelo Decreto n ${ }^{\circ} 6.049 / 2007$, traz em seu Título $\mathrm{X}$ as regras quanto à visitação e aos atendimentos com advogado. As visitas "de parentes, do cônjuge ou do companheiro de comprovado vínculo afetivo" são asseguradas, porém, condicionadas à autorização do Diretor do estabelecimento. Podendo ter duração de 3 (três) horas, as visitas são geralmente realizadas uma vez por semana.

A visita íntima, embora prevista no art. 95 do Regulamento, deve ser "regulamentada pelo Ministério da Justiça”. Em 2017 foi publicada a Portaria no 718 do Ministro da Justiça, que restringiu a visita íntima aos presos delatores ou colaboradores premiados, o que, na realidade, pode ter significado um ponto final no assunto, vez que não foi localizada nenhuma informação acerca de presos que foram inclusos no Sistema na condição de delatores ou colaboradores premiados.

Em 2019, o então Ministro da Justiça e Segurança Pública Sérgio Moro editou a Portaria $\mathrm{n}^{\mathrm{o}}$ 157, publicada em 12 de fevereiro de 2019, que "disciplina o procedimento de visita social aos presos nos estabelecimentos penais federais de segurança máxima e dá outras providências", determinando que "visitas sociais nos estabelecimentos penais federais de segurança máxima serão restritas ao parlatório e por videoconferência”, sendo a visita "assegurada ao cônjuge, companheira, parentes e amigos, separados por vidro, garantindo-se a comunicação por meio de interfone".

Até a publicação da Portaria n ${ }^{\circ} 157$, as visitas de cônjuges, companheiras e parentes eram realizadas em pátios de visitas, excepcionados os casos em que o visitante fosse réu em ação judicial, quando, então, tinha a visita restrita ao parlatório.

Embora legalmente assegurada, ainda que com diversas restrições, a manutenção do vínculo familiar e social do preso com seus familiares e amigos enfrenta problemas práticos de difícil superação.

Outros obstáculos são somados a este, na efetivação dos direitos dos presos, o que será melhor descrito no tópico seguinte.

Obstáculos impostos à efetivação das garantias individuais relacionadas aos vínculos dos presos com seus familiares 
O espaço não permite adentrar na análise minuciosa de cada característica do Sistema Penitenciário Federal e de suas unidades que culminam na mitigação ou óbice do gozo de certos direitos e garantias individuais. Mas ainda é possível discorrer, ainda que superficialmente, sobre alguns exemplos mais expostos.

O primeiro ponto, que merece um estudo detalhado, é no tocante ao direito de assistência da família (CF, art. $5^{\circ}$, inc. LXIII), direito este que a LEP intenta proteger também com seu art. 103. Tais direitos têm sua efetivação prática dificultada a níveis que, por vezes, são insuperáveis, em razão da distância geográfica.

As cinco penitenciárias federais estão distribuídas pelo país, em diferentes regiões, e foram idealizadas para afastar o preso de seu meio social, de forma que é comum que presos oriundos de prisões estaduais da região nordeste do país, por exemplo, sejam custodiados nas penitenciárias federais de Porto Velho-RO, Catanduvas - PR e Campo Grande - MS, distantes vários quilômetros de seus familiares.

A Figura 3, que ilustra o artigo "Conheça o Sistema Penitenciário Federal” (2019), disponível no Portal Governo do Brasil permite melhor dimensionar esta questão, quando se percebe a distância entre as penitenciárias federais:

Figura 3

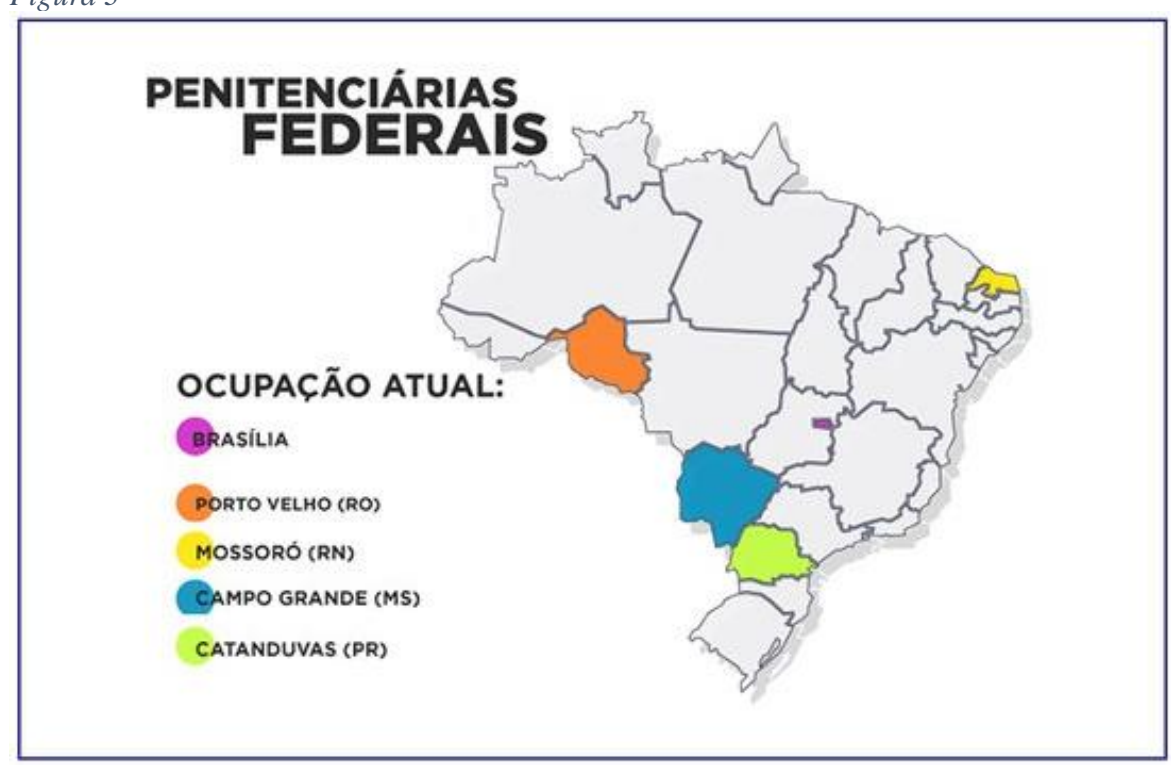

Fonte: BRASIL. Governo Federal. Conheça o Sistema Penitenciário Federal. 2019. Disponível em: <https://www.gov.br/pt-br/noticias/justica-e-seguranca/2019/12/conheca-o-sistema-penitenciario-federal >. Acesso em 10 maio 2021.

Esse afastamento do preso, levado para longe de seu meio social e familiar, embora tenha o claro objetivo de desarraigá-lo do convívio em que estava estabelecido, para enfraquecer laços 
que o levaram ou o mantiveram na prática de crimes, acabou por ter um efeito reverso, a longo prazo.

É o que explica Luiz Carlos Valois (2021, p. 120):

No sistema penitenciário, o preso que vai para uma penitenciária federal ganha o status de preso importante, importante para o Estado, importante como liderança, e, mesmo que anteriormente ele, o preso, fosse apenas um líder de pavilhão, coisa que sempre existiu desde que prisão é prisão, voltará realmente pronto para assumir a condição de líder de uma facção. [...]

Tal fato pudemos presenciar no Amazonas. Antes da transferência de presos para penitenciárias federais, procedimento contra o qual nos opusemos, não se falava em facções, o que veio a acontecer justamente quando do retorno dos primeiros presos à Manaus, época em que passou-se a ouvir falar em PCC, Primeiro Comando da Capital, facção originária de São Paulo, e a FDN, Família do Norte, aparentemente facção nascida no próprio Amazonas em oposição à primeira.

Além disso, como os presos nas penitenciárias federais estão suscetíveis a transferências entre as penitenciárias, como já mencionado, caso algum familiar se muda para a cidade da penitenciária onde o preso está custodiado, a fim de acompanha-lo, o faz sabendo que o preso poderá ser levado a qualquer outra das penitenciárias federais, a qualquer momento, sem aviso prévio.

Inclusive, em matéria já citada (Construtora faz entrega provisória da Penitenciária Federal de Brasília ao Depen) é mencionada a habitualidade do rodízio de presos, "fazendo com que seus visitantes não fixem residência nas proximidades das penitenciárias".

Luiz Carlos Valois (2021, p. 59) sugere que a distância entre as penitenciárias federais e o meio social e familiar do preso nela incluídos merece ressalvas:

Na vedação à pena de banimento [...] também há que se ter uma interpretação moderna à Constituição Federal, para entender que nossa carta maior não permite que o sentenciado seja afastado de sua comunidade, seja considerado um não cidadão, ou perca o contato com a família.

Se assim puder ser interpretada a Constituição Federal, como pensamos ser o caso, o envio de presos para as penitenciárias federais distantes da cidade e do Estado de origem do condenado, do local onde reside sua família, como permite a norma do inc. VI, do art. 75 da LEP, deveria ser considerada igualmente inconstitucional.

Assim, a família, que deveria receber "especial proteção do estado" (CF, art. 226), acaba por ser separada, não por negligência estatal, mas de forma deliberada, fruto da ação intencional e consciente dos poderes públicos.

Além do impasse gerado pela distância geográfica, os presos podem encontrar outros óbices, melhor delineados quando se observam os processos judiciais relacionados ao Sistema Penitenciário Federal. 
Judicialização dos conflitos entre as garantias individuais e a segurança pública

Como mencionado anteriormente, a localização geográfica e a rotina das penitenciárias federais podem culminar em conflitos entre os interesses do Estado e os direitos da pessoa custodiada e seus familiares.

É o caso do processo que será analisado na sequência, que tramitou perante a Seção de Execução Penal de Catanduvas, da Seção Judiciária do Paraná, do Tribunal Regional Federal da $4^{\mathrm{a}}$ Região. O processo trata de fato ocorrido na Penitenciária Federal em Catanduvas-PR, antes das suspensões excepcionais da pandemia.

No caso, autuado sob o n ${ }^{\circ}$ 5043529-20.2019.4.04.7000, um preso de religião muçulmana relata problema enfrentado por sua mãe, praticante da mesma fé, quando foi visita-lo. Em sua petição, afirma que a mãe acredita na "necessidade do uso do véu [hijab]", e, a despeito de sua fé, “a Direção da Penitenciária Federal em Catanduvas - PR a obriga a retirar o Hijab e permanecer sem ele durante as visitas".

Foi argumentado que o hijab não é diferente de outras peças de vestimenta, e que "todas as visitas devem permanecer vestidas, e tudo o que pode ser oculto em um véu posto na cabeça pode ser oculto também em um casaco, uma blusa, um 'top' ou sutiã', no que pode ser interpretado como uma tentativa de receber tratamento isonômico aos demais, professantes de uma fé cristã, sabidamente dominante no país.

O preso, no caso, comparou ainda a situação ao ato de "obrigar uma freira a retirar o véu em eventual trabalho de assistência religiosa", e relatou a dificuldade de se ver entre deixar de receber as visitas maternas ou vê-la pecando para visitá-lo, o que pode ser compreendido quando se considera a importância do uso do hijab na cultura muçulmana, onde representaria, para a mulher, "um símbolo máximo, digamos assim, de expressão ou exteriorização de sua fé e religiosidade" (PAIVA, 2018, p. 106).

Chamada a responder no processo, sobre a proibição do uso do hijab, a Direção da Penitenciária apresentou que "o procedimento de segurança para a entrada nas dependências da Penitenciária Federal é obrigação legal a todos imposta, sendo proibida a entrada com pertences pessoais que dificulte ou impossibilite a inspeção manual e visual de segurança".

Assim, embora o preso tenha invocado a garantia constitucional da liberdade de crença, foi proferida decisão judicial com fundamento cujo argumento principal pode ser observado no seguinte parágrafo: 
Não há proporcionalidade e/ou razoabilidade em se expor a PFCAT a perigo extremo (considerando a possibilidade de ocultação de objetos, como aparelhos celulares, drogas e armas no véu) para que a visitante não sofra um desgosto/aborrecimento momentâneo pela transgressão de um costume.

Com a decisão, foi interposto o recurso de Agravo em Execução Penal, no qual o preso visava combater os argumentos da decisão judicial de primeiro grau.

Ao expor os motivos do recurso, o preso novamente invocou as garantias constitucionais, a Convenção Americana dos Direitos Humanos, e reforçou a afirmação de inexistência de maiores riscos à segurança pelo uso do hijab.

Consta nas razões do recurso que "o risco que o véu oferece é o mesmo que todas as demais roupas oferecem, sendo que proibir apenas o hijab revela jugo desigual para deferentes crenças religiosas", e mais:

mesmo que se entenda necessária a revista pessoal - inclusive a vexatória - nenhuma visita é forçada a entrar nua na penitenciária. Portanto, se é possível que uma servidora realize a revista na visitante, e no hijab, qual a razoabilidade em proibir a entrada com a peça de roupa?

$[\ldots]$

Ora, aparelhos celulares, drogas e armas podem ser ocultados em QUALQUER peça de roupa, não sendo possibilidade exclusiva do hijab. Portanto, qual a diferença entre a mulher que usa calça, blusa e hijab, e a mulher que usa calça e blusa? Nenhuma, que não a opção religiosa.

$[\ldots]$

Ressalta-se que o direito do uso do hijab não veda as medidas de segurança que são aplicadas aos demais, de forma que para a segurança continuarão sendo usados os 3 (três) detectores de metal da Unidade, o scanner corporal e, quando necessária, a revista pessoal, na qual uma servidora poderá verificar o item do vestuário sem a necessidade condenar a visitante à humilhação religiosa de ficar sem o véu perante vários desconhecidos por várias horas.

No Tribunal Regional Federal da $4^{\mathrm{a}}$ Região, a Procuradoria Regional da República da $4^{\mathrm{a}}$ Região deu o seu parecer, pelo desprovimento do recurso, considerando que:

liberdade de crença e culto, um dos pilares do estado democrático, não pode ser tida como um valor absoluto, devendo ceder quando em confronto com a necessidade de se manter a segurança, a integridade de todas as pessoas presentes no estabelecimento prisional e, em última análise, até mesmo a vida de todos.

A decisão do Tribunal foi no mesmo sentido, negando provimento ao recurso e mantendo a proibição.

Outro direito cujo gozo encontra obstáculos nas penitenciárias federais é o do banho de sol. 
Recentemente o a Segunda Turma do Supremo Tribunal Federal proferiu decisão emblemática em um Habeas Corpus impetrado pela Defensoria Pública do Estado de São Paulo, determinando que fosse assegurado a todos os presos, "especialmente aos recolhidos nos pavilhões de medida preventiva de segurança pessoal ("Pavilhão de Seguro") e disciplinar ("Pavilhão Disciplinar"), o direito à saída da cela pelo período mínimo de 02 (duas) horas diárias para banho de sol”' (HC 172136 SP, acórdão, peça 257, p. 57).

Quando concedida a ordem de forma liminar (em $1^{\text {o }}$ de julho de 2019, peça 11 dos autos eletrônicos), alguns presos do Sistema Penitenciário Federal apresentaram pedido de extensão (peças 12 e 16). Um deles aduz ter sido transferido para a Penitenciária Federal em Brasília no dia de 17 de outubro de 2018, sendo que:

Desde tal data se encontra em REGIME DISCIPLINAR DIFERENCIADO (PRAZO DE 360 DIAS), SEM DIREITO A SAÍDA DA CELA PARA BANHO DE SOL, tendo direito apenas a acesso a um pequeno espaço na cela onde há melhor iluminação, haja vista armação de concreto que tapa a entrada de raios solares. (HC 172136 SP, peça 16, p. 2).

Analisando o pedido, o Relator do processo decidiu:

Constato, desse modo, que há entre os reclusos nos pavilhões destinados à execução de medida preventiva de segurança pessoal e disciplinar da Penitenciária "Tacyan Menezes de Lucena", em Martinópolis/SP, e o ora requerente identidade de situação, o que viabiliza o deferimento do pedido de extensão. [...]

Determino, ainda, que o Senhor Diretor Técnico responsável pela administração da Penitenciária Federal em Brasília/DF, no prazo de 30 (trinta) dias, informe e detalhe as medidas que, ordenadas nesta decisão, objetivam viabilizar a implementação do direito do recluso, ora requerente, à saída da cela por 02 (duas) horas diárias para banho de sol.

Notificado, o DEPEN expediu ofício ao Ministro Gilmar Mendes, no qual postula a revogação da liminar, entre outras justificativas, pela "ausência de similitude fática" e a "inviabilidade de operacionalizar a retirada, de forma individual, de cada interno em regime disciplinar diferenciado para banho de sol diário em pátio coletivo" (peça 226 - Ofício no 373/2020/DIPF-BRA/PFBRA/DISPF/DEPEN/MJ).

No mesmo ofício, apresenta imagens comparando a cela destinada ao RDD, conforme Figura 4 - com espaço para entrada da luz solar, e a cela comum: 


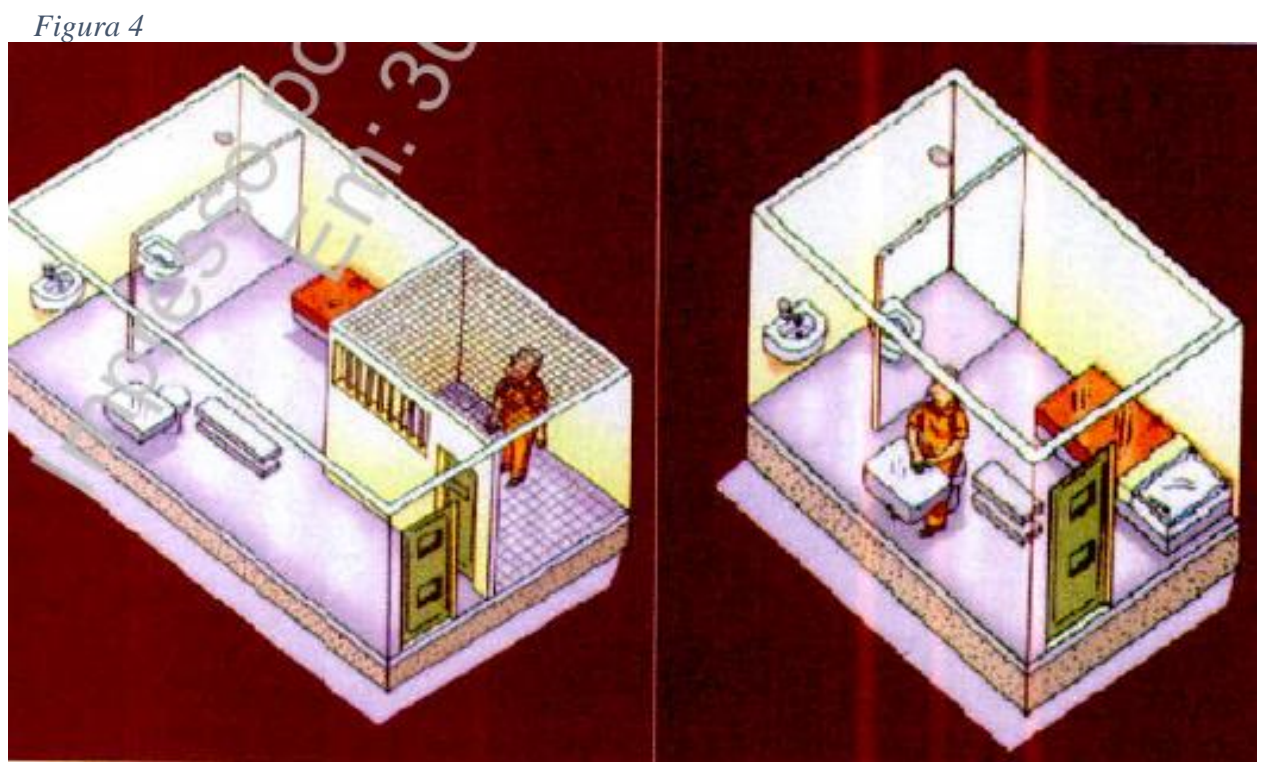

Fonte: Supremo Tribunal Federal; HC 172136 SP; autos eletrônicos, peça 226.

No acórdão (peça 257) não houve revogação da liminar, mantendo-se a decisão.

Percebe-se, assim, que o usufruto dos direitos mais básicos, como o de banho de sol, podem encontrar resistência nas penitenciárias federais, desaguando em lides judiciais.

Embora curto o espaço, crê-se que os processos analisados foram suficientes para entendermos um pouco mais sobre os conflitos de interesses e a dinâmica da autoridade pública no âmbito do Sistema Penitenciário Federal.

Estas informações parecem reforçar afirmação feita pelo Tribunal de Contas da União, no ano de 2017, sobre o Sistema Penitenciário Federal, em estudo do Acompanhamento da Execução das Penas:

Foi analisado, também, se o acompanhamento da execução das penas está em conformidade com o previsto na Lei 12.714, de 2012. A realidade encontrada foi: há falta de informações confiáveis acerca dos detentos; o modelo do sistema federal desenhado pelo Depen não prevê todos os elementos prenunciados na lei; e há atrasos e entraves no processo de desenvolvimento do sistema.

A análise conjunta das normas vigentes e das peças processuais dos autos citados permite perceber que o Sistema Penitenciário Federal é cenário de tensão entre a garantia dos direitos individuais dos presos e o resguardo da segurança pública pela autoridade estatal.

\section{Conclusão}


Neste breve estudo, foi perceptível que os questionamentos envolvendo o Sistema Penitenciário Federal não são de fácil desenlace, sendo que há sempre o peso de suas penitenciárias se tratarem de instituições de segurança máxima.

Não obstante, o argumento do resguardo da segurança pública, da lei e da ordem não pode se constituir de justificativa para afastar a população da realidade vivida nas penitenciárias federais, que, embora sejam projetadas para viabilizar o máximo isolamento entre o preso e o meio social e familiar de onde foi retirado, nem por isso deixam de ser instituições pertencentes a um Estado Democrático de Direito.

Assim, é possível concluir que o Sistema Penitenciário Federal, especialmente por ter sido criado muito recentemente, ser desconhecido por grande parte da população e por estar em constante evolução, carece de aprofundada análise, de forma a viabilizar o desenvolvimento de críticas que conduzam a organização para um destino onde sejam melhor sustentados os diversos bens jurídicos que deve proteger: o cumprimento das decisões judiciais, a segurança pública, os direitos previstos na Lei de Execução Penal e as garantias individuais dos presos e seus familiares.

\section{Referências}

BRASIL. Autoridades propõem mudanças legais no Sistema Penitenciário Federal. Conselho de Justiça Federal, 201. Disponível em: https://www.cjf.jus.br/cjf/noticias/2011/maio/autoridades-propoem-mudancas-legais-nosistema-penitenciario-federal>. Acesso em: 10 de agosto de 2021.

BRASIL. Conselho da Justiça Federal, Corregedoria-Geral da Justiça Federal; Departamento Penitenciário Nacional. I Workshop sobre o Sistema Penitenciário Federal: enunciados. Brasília: CJF，2010. Disponível em: < https://www.cjf.jus.br/cjf/corregedoria-da-justicafederal/centro-de-estudos-judiciarios-1/publicacoes-1/sistema-penitenciario-federal>. Acesso em 25 jul. 2018.

BRASIL. Conselho da Justiça Federal, Corregedoria-Geral da Justiça Federal; Departamento Penitenciário Nacional. IV Workshop sobre o Sistema Penitenciário Federal: enunciados. Fórum Permanente do Sistema Penitenciário Federal, Brasília: CJF, 2013. Disponível em: < 
https://www.cjf.jus.br/cjf/corregedoria-da-justica-federal/centro-de-estudos-judiciarios1/publicacoes-1/sistema-penitenciario-federal>. Acesso em 25 jul. 2018.

BRASIL. Conselho da Justiça Federal, Corregedoria-Geral da Justiça Federal; Centro de Estudos Judiciários da Justiça Federal. Plano de Gestão das Corregedorias Judiciais das Penitenciárias Federais. Fórum Permanente do Sistema Penitenciário Federal, Brasília: CJF. Disponível em: <https://www.cjf.jus.br/cjf/corregedoria-da-justica-federal/centro-de-estudosjudiciarios-1/publicacoes-1/sistema-penitenciario-federal>. Acesso em 25 jul. 2018.

BRASIL. Conselho da Justiça Federal, Corregedoria-Geral da Justiça Federal; Centro de Estudos Judiciários da Justiça Federal. Manual Prático de Rotinas das Corregedorias Judiciais das Penitenciárias Federais. Fórum Permanente do Sistema Penitenciário Federal, Brasília: CJF, 2013. Disponível em: <https://www.cjf.jus.br/cjf/corregedoria-da-justicafederal/centro-de-estudos-judiciarios-1/publicacoes-1/sistema-penitenciario-federal>. Acesso em 25 jul. 2018.

BRASIL. Conselho Nacional de Justiça. Calculando custos prisionais: panorama nacional e avanços necessários. coordenação de Luís Geraldo Sant'Ana Lanfredi et al. Brasília: Conselho Nacional de Justiça, 2021. Disponível em: < https://www.cnj.jus.br/wpcontent/uploads/2021/11/calculando-custos-prisionais-panorama-nacional-e-avancosnecessarios.pdf>. Acesso em: 30 de novembro de 2021.

BRASIL. Decreto no 6.049, de 27 de fevereiro de 2007. Brasília-DF, 2007.

BRASIL. Decreto no 6.877, de 18 de junho de 2009. Brasília-DF, 2007.

BRASIL. Departamento Penitenciário Nacional. Coordenação Geral de Classificação, Movimentação e Segurança Penitenciária. Disponível em: <http://antigo.depen.gov.br/DEPEN/dispf/cgcmsp>. Acesso em: 29 de novembro de 2021.

BRASIL. Governo Federal. Conheça o Sistema Penitenciário Federal. 2019. Disponível em: <https://www.gov.br/pt-br/noticias/justica-e-seguranca/2019/12/conheca-o-sistemapenitenciario-federal>. Acesso em 10 maio 2021.

BRASIL. Lei no 11.671, de 08 de maio de 2008. Brasília-DF, 1990.

BRASIL. Lei no 13.769 de 19 de dezembro de 2018. Brasília-DF, 2018. 
BRASIL. Lei no 7.210 de 11 de julho de 1984. Brasília-DF, 1984.

BRASIL. Lei no 8.072, de 25 de julho de 1990. Brasília-DF, 1990.

BRASIL. Ministério da Justiça e Segurança Pública. Como funciona um presídio federal. Brasília, 2018. Disponível em: <http://www.justica.gov.br/news/entenda-como-funciona-umpresidio-federal>. Acesso em 30 dez. 2018.

BRASIL. Ministério da Justiça e Segurança Pública. Construtora faz entrega provisória da Penitenciária Federal de Brasília ao Depen. Brasília, 2017. Disponível em: < https://www.justica.gov.br/news/construtora-faz-entrega-provisoria-da-penitenciaria-federalde-brasilia-ao-depen>. Acesso em: 29 de novembro de 2021.

BRASIL. Ministério da Justiça e Segurança Pública. Manual de Assistências do Sistema Penitenciário Federal. Portaria DISPF no 11, de 04 de dezembro de 2015. Brasília, 2015. Disponível em: < http://depen.gov.br/DEPEN/dispf/cgtp/ManualdeAssistenciasdoSPF.pdf>. Acesso em 10 mar. 2019.

BRASIL. Ministério da Justiça e Segurança Pública. Ministro entrega viaturas e anuncia presídio federal no Rio Grande do Sul. Brasília, 2017. Disponível em: $<$ http://www.justica.gov.br/news/ministro-entrega-viaturas-e-anuncia-presidio-federal-no-riogrande-do-sul>. Acesso em 28 dez. 2018.

BRASIL. Ministério da Justiça e Segurança Pública. Rotina Operacional Padrão (Rop) Psicologia. $\quad 2019 . \quad$ Brasília, Disponível em: <http://www.antigo.depen.gov.br/DEPEN/dispf/cgtp/normativos/ProcedimentoOperacionalPa droPsicologia.pdf>. Acesso em: 31 maio 2021.

BRASIL. Supremo Tribunal Federal. HC 172136. Preponderância do "mínimo existencial" - o direito à saída da cela por 02 (duas) horas diárias para banho de sol como prerrogativa inafastável. Defensoria Pública do Estado de São Paulo versus Relatora do HC No 269.265 do Superior Tribunal de Justiça. Relator: Min. Celso de Mello. Brasília, 10 de outubro de 2020. Processo Eletrônico DJe-283, publicado em 01 de dezembro de 2020.

BRASIL. Tribunal de Contas da União. Realidade prisional: auditoria mostra que o custo mensal do preso é desconhecido em vários Estados. Brasília, 2017. Disponível em: $<$ https://portal.tcu.gov.br/imprensa/noticias/realidade-prisional-auditoria-mostra-que-o-customensal-do-preso-e-desconhecido-em-varios-estados.htm>. Acesso em: 22 out. 2020. 
BRASIL. Tribunal Regional Federal da $4^{a}$ Região. Petição administrativa no 504352920.2019.4.04.7000. Akram Abder Rahim Hamider versus Penitenciária Federal de Catanduvas. Processo Eletrônico.

BRITO, Luísa. Presídio para Beira-Mar ainda está em obras. Folha de São Paulo, São Paulo, 15 de jul. 2005. Disponível em: < https://www1.folha.uol.com.br/fsp/cotidian/ff1507200501.htm>. Acesso em: 18 jan. 2019.

LIMA, Bruna. Líderes do PCC são os primeiros presos da nova penitenciária em Brasília. Correio Braziliense, Brasília, 17 de out. 2018. Disponível em: <https://www.correiobraziliense.com.br/app/noticia/cidades/2018/10/17/interna_cidadesdf,71 3408/lideres-do-pcc-sao-os-primeiros-presos-da-nova-penitenciaria.shtml>. Acesso em: 30 jan. 2019.

PAIVA, Daniele Alves. Usos e percepções a respeito do véu islâmico (hijab) entre muçulmanas no Ceará. 2018. 115f. - Dissertação (Mestrado) - Universidade Federal do Ceará, Programa de Pós-graduação em Sociologia, Fortaleza (CE), 2018.

PAIXÃO, Juliana Maria da; SILVA JÚNIOR, Walter Nunes da. Cartilha das Corregedorias judiciais das penitenciárias federais. Fórum Permanente do Sistema Penitenciário Federal. Brasília: Conselho da Justiça Federal, Centro de Estudos Judiciários, 2013.

SANTOS, Gabriel Cesar dos. Sistema Penitenciário Federal e a violação dos direitos individuais do preso: uma reflexão crítica sobre os critérios de seleção dos inimigos do estado brasileiro. Revista da Defensoria Pública da União, Brasília, n. 9, p. 305-334, 2016. Disponível em: < https://revistadadpu.dpu.def.br/index.php/revistadadpu/article/view/86/71>. Acesso em: 21 mai. 2018.

STACCIARINI, Isa. Penitenciária federal de segurança máxima será inaugurada nesta terça no DF. Correio Braziliense, Brasília, 15 de out. 2018. Disponível em: <https://www.correiobraziliense.com.br/app/noticia/cidades/2018/10/15/interna_cidadesdf,71 2836/penitenciaria-federal-de-seguranca-maxima-sera-inaugurada-no-df.shtml>. Acesso em: 30 jan. 2019.

VALOIS, Luís Carlos. Processo de execução penal e o estado de coisas inconstitucional. 2. Ed. Atual. Com base na Lei 13.694/19. Belo Horizonte, São Paulo: D’Plácido, 2021. 